\title{
ASCITE QUILOSA TRAUMÁTICA
}

\author{
TRAUMATIC CHYLOUS ASCITES
}

\section{João Baptista de Resende Neto ${ }^{1}$ Daniel Mendes Pinto, ACBC - MG $^{2}$ Wilson Luiz Abrantes, TCBC - MG ${ }^{3}$}

\section{INTRODUÇÃO}

A ascite quilosa por trauma abdominal é uma entidade clínica pouco freqüente, principalmente na infância. Na literatura de língua inglesa, entre adultos e crianças, existem menos de 100 casos publicados. A etiologia na maioria dos casos é congênita ou idiopática. O traumatismo abdominal é a causa menos freqüente, sendo responsável por $10 \%$ dos casos de ascite quilosa ${ }^{1}$. O presente caso ocorreu em criança, após trauma contuso. $\mathrm{O}$ tratamento realizado foi a ligadura de ductos linfáticos lesados.

\section{RELATO DO CASO}

Uma criança hígida do sexo masculino, com seis anos de idade, ocupava o banco traseiro de um veículo. Houve colisão frontal com outro automóvel, com três mortes instantâneas de adultos. O paciente foi trazido ao nosso hospital por transeuntes.

$\mathrm{Na}$ admissão apresentava freqüência cardíaca de 130bpm, pressão arterial 95/60mmHg, e freqüência respiratória 32inc/min. Vias aéreas pérvias. Escala de Glasgow de 15. Apresentava também contusão maxilofacial, avulsão parcial do lábio superior e fratura fechada do fêmur esquerdo. Abdome livre, ligeiramente distendido. Radiografia simples da coluna cervical e tomografia computadorizada (TC) do encéfalo normais. Ultra-sonografia (US) abdominal revelou pequena quantidade de líquido livre na goteira parietocólica esquerda. Não foram evidenciadas lesões do fígado ou do baço. A TC de abdome demonstrou uma pequena quantidade de líquido no espaço retroperitoneal e na cavidade abdominal, sem lesões de vísceras sólidas.

Nova avaliação clínica feita uma hora após admissão revelou abdome tenso com poucos ruídos hidroaéreos.
Novo US abdominal mostrou aumento do líquido livre na cavidade abdominal. A frequiência cardíaca aumentou para 140bpm, com um déficit de base de - $9 \mathrm{mmol} / \mathrm{L}$ à gasometria. Após ter recebido $20 \mathrm{ml} / \mathrm{kg}$ de solução cristalóide aquecida, a criança foi levada à cirurgia. À laparotomia, encontramos $400 \mathrm{ml}$ de secreção cremosa brancacenta, opalescente. Na raiz do mesentério havia extravasamento de linfa, sem laceração do mesmo. O retroperitôneo apresentava-se abaulado. Uma lesão seromuscular foi notada na parede anterior do cólon transverso. O retroperitôneo foi aberto no nível da raiz do mesentério e os ductos linfáticos foram laqueados com chuleio simples com fio de polipropileno 4-0. A lesão seromuscular do cólon transverso foi tratada com sutura contínua. A abertura do retroperitôneo e a cavidade abdominal foram fechadas, sem colocação de drenos. A fratura distal do fêmur foi tratada por tração esquelética.

A análise química do fluido retroperitoneal evidenciou: albumina $=3,8 \mathrm{~g} / \mathrm{dl}$, glicose $=100 \mathrm{mg} / \mathrm{dl}$, triglicerídeos $=1.981 \mathrm{mg} / \mathrm{dl}$, gravidade específica de 1.020 e $\mathrm{pH}$ de 7,7. Não houve crescimento de bactérias nessa secreção.

A criança foi encaminhada à unidade de tratamento intensivo, em ventilação mecânica. No sétimo dia de pósoperatório surgiu febre com abscesso na ferida cirúrgica que exigiu drenagem e antibioticoterapia com oxacilina e metronidazol. No nono dia de pós-operatório houve evisceração. À nova laparotomia constatou-se: distensão significativa de alças, e abscesso retroperitoneal de $50 \mathrm{ml}$ na raiz do mesentério. Não foi observada drenagem de linfa durante a cirurgia. $\mathrm{O}$ abscesso foi drenado com dois drenos tipo Penrose.

O edema e a distensão do intestino impediram o fechamento da laparotomia. Decidiu-se então pela laparostomia com utilização de bolsa plástica de soro fisiológico. Realizou-se uma traqueostomia para facilitar o tratamento do traumatismo maxilofacial. No $20^{\circ}$ dia de pós-opera-

1. Cirurgião dos Hospitais João XXIII e Mater Dei, Belo Horizonte. Fellow em Cirurgia do Trauma e Terapia Intensiva pela Boston University, USA.

2. Cirurgião do Hospital João XXIII, Belo Horizonte. Membro Associado do Colégio Brasileiro de Cirurgiões

3. Chefe do Serviço de Cirurgia Geral e do Trauma do Hospital João XXIII. Membro Titular do Colégio Brasileiro de Cirurgiões.

Recebido em 18/10/2000

Aceito para publicação em 25/11/2001

Trabalho realizado no Hospital João XXIII, Belo Horizonte, MG. 
tório, a criança foi liberada do CTI, tolerando dieta oral. O paciente recebeu alta hospitalar no 41ㅇ dia de pós-operatório. Um mês após foi revisto, constatando-se apenas hérnia incisional que será tratada posteriormente.

\section{DISCUSSÃo}

A linfa é produzida nos linfáticos do intestino delgado, por absorção dos produtos da ingestão de gorduras. A taxa basal de produção é de $1 \mathrm{ml} / \mathrm{k} / \mathrm{h}$. Após uma refeição rica em gorduras a produção de linfa pode chegar a $200 \mathrm{ml} / \mathrm{kg} / \mathrm{h}$. É transportada para a cisterna do quilo e posteriormente para o ducto torácico. Quando ocorre obstrução linfática adquirida ou congênita, a linfa pode ser encontrada fora desses vasos na forma de ascite.

Em pacientes adultos, as neoplasias são as causas mais freqüentes de obstrução linfática ${ }^{1}$. O trauma é a causa menos freqüente e responde por $10 \%$ das ascites quilosas $^{1,2}$. A lesão é ocasionada por trauma direto sobre o abdome com compressão súbita e ruptura dos linfáticos mesentéricos. Há relatos de ascite quilosa por esse mecanismo em crianças espancadas ${ }^{3}$. Na literatura de língua inglesa foram relatados 12 casos de ascite quilosa em ciranças decorrentes de traumatismos abdominais fechados, inclusive os casos de espancamento ${ }^{1,2,4}$. Na criança não é necessária uma força traumática muito intensa para levar à ruptura dos linfáticos, principalmente se o trauma ocorrer no período pós-prandial, quando os canais de linfa estão engurgitados. A ascite quilosa desenvolve-se mais comumente no mesentério do intestino delgado ${ }^{2,5}$.

Como a linfa causa pouca irritação peritoneal, a sintomatologia é pouco expressiva e o médico examinador tende à conduta expectante. O líquido colhido por paracentese normalmente apresenta alta concentração de gorduras $(0,4 \%$ a $4,0 \%)$, gravidade específica acima de 1.012 , proteínas totais acima de $3 \%$, glóbulos de gordura tingidos pelo Sudam III e pH alcalino ${ }^{3,5}$.

O US abdominal é inespecífico para o diagnóstico da ascite quilosa. Na tomografia, as densidades de hemorragia aguda são diferentes das de linfa, tornando o diagnóstico não invasivo possível ${ }^{5}$. Linfangiografia e linfocintilografia com tecnécio 99 têm sido usadas para diagnóstico de ascite quilosa devido a anormalidades congênitas, obstrução, traumatismos e neoplasias. São alternativas tecnicamente difíceis e as salas de emergência não são locais ideais para esses métodos invasivos.

Se o tratamento clínico é tentado, o uso de dieta com baixo consumo de gordura e alto de proteínas ou triglicerídeos de cadeia média e paracenteses têm conseguido algum sucesso. A nutrição parenteral total pode ser também utilizada, provocando uma redução progressiva da produção linfática nas áreas onde existe drenagem, enquanto a oferta de calorias ao paciente é mantida ${ }^{1,3}$.

Quando a produção de linfa excede a 1 litro/dia, através de paracentese, durante os primeiros cinco dias, o diagnóstico de uma lesão de correção cirúrgica é o mais provável. Caso não ocorra melhora clínica com tratamento conservador em quatro semanas, uma linfangiografia deve ser realizada ${ }^{1,5}$. O tratamento definitivo será feito através de laparotomia exploradora.

Nos casos de lesões traumáticas, a exploração cirúrgica com ligadura de linfáticos lesados é a forma mais adequada de tratamento quando há suspeita de lesões associadas.

\begin{abstract}
Chylous ascites is a rare clinical entity. In infancy it is less commom still. The etiology of most of them is usually congenital or idiopathic; trauma is a less frequent cause. It has been implicated in about $10 \%$ of all cases ${ }^{1-5}$. There have been less than one hundred cases published in the English literature, including 12 in children. We report a pediatric case of chylous ascites as a result of blunt abdominal trauma managed by ligation of the lymphatic leak.
\end{abstract}

Key Words: Chylous ascites; Abdominal trauma; Child.

\section{REFERÊNCIAS}

1. Cochran WJ, Klish WJ, Brown MR et al. Chylous ascites in infants and children: a case report and literature review. J Pediatr Gastroenterol Nutr. 1985; 4: 668-683.

2. Beal AL, Gormley CM, Gordon DL et al. Chylous ascites: a manifestation of blunt abdominal trauma in an infant. J Pediatr Surg. 1998; 33: 650-652.

3. Benhaim, P, Strear C, Knudson M et al. Posttraumatic chylous ascites in a child: recognition and management of an unusual condition. J Trauma. 1995; 39: 1175-1177.

4. Boysen BE. Chylous ascites: manifestation of the battered child syndrome. Am J Dis Child. 1975; 129: 1338-1339.

5. Beeson R, Gottrand F, Saurier P et al. Traumatic chylous ascites: conservative management. J Pediatr Surg. 1992; 27: 1543.
6. Maurer CA, Wildi S, Müller MF et al. Blunt abdominal trauma causing chyloretoperitoneum. J Trauma. 1997; 43: 696-697.

Endereço para correspondência:

João Baptista de Rezende Neto

Rua Matipó 333, apto. 401, Bairro Santo Antônio

30.350-210 - Belo Horizonte-MG 